\title{
The Gadfly: A Collaborative Approach to Doing Data Differently
}

\author{
Sarah Healy and Caroline Morrison
}

\begin{abstract}
The Gadfly first materialised as a provocative data performance at the Transitions Research Symposium held at The University of Melbourne in June 2017. The figuration of gadfly in the title shapes the figure of the researcher as (bothersome) questioner that provokes critical dialogue about the assumptions underpinning our own research practices and learning environments research more generally. This figuration provides us an entry point into working data through approaches offered by new materialist and post-qualitative research methods. The resulting data performance came together as a collaborative experiment inhabiting the in-between spaces of researchers, participants, research contexts, and 'data' initially generated in a Taekwondo training assemblage. Our collaborative approach involved an intraactive process as a way of doing data differently. Informing our process are concepts of intra-action, assemblage, affect, and sticky data.
\end{abstract}

\section{Introduction}

This chapter shows learning environments research being done differently. It explores the educational world through different conceptual lenses to those ordinarily used, and shows how alternative figurations of research and the researcher emerge. Where the figuration of the researcher in much educational research is of the 'objective analyst', the figuration at work in this chapter is of the gadfly as provocative questioner.

\section{Enter the Gadfly}

Socrates referred to himself as a gadfly - a horsefly with a nasty bite that, while irritating, did not do serious harm. Gadfly has a history. It connects thought across space-times; from provocatively questioning the wisdom of the citizens of Athens of

\footnotetext{
S. Healy $(\varangle) \cdot$ C. Morrison

The University of Melbourne, Melbourne, Australia

e-mail: healysaz@gmail.com 
the past (Plato, 1984), into the present, in our questioning and probing research data as we think-write differently in an experimental collaborative approach. The Spinozist and Deleuzean understanding that is forwarded in our experimental collaborative approach is of gadfly as a milieu of thought; other milieu being nomad, hermit, shadow, and border (Deleuze, 1988).

We draw on the figuration of the gadfly to question-and be questioned bydata. The purpose is to open methodological thinking-doing in learning environments research. We press this point because we believe that without methodological diversity, learning environments research risks reproducing 'self-limiting knowledge' (Elmore, 2018) of what they are, and how teachers as individual human subjects make them work (or resist their pedagogic potential). The problem as we 'see' it, is that research beginning with pre-existing assumptions of what and who objects and subjects are can lead to an oversimplification of the complex 'materialising processes of learning' (Mulcahy, 2018, p. 14). It can also lead to privileging the social while neglecting the contingent agencies of a range of participants in learning processes; for example: technologies, material objects, learning bodies, teaching bodies, and the consequential affectivities that flow in and between them.

To expand our view of what learning environments research could achieve, we turn to case studies of Science, Technology and Society (STS) which show empirically that society and nature (subjects and objects) are not separate from one another (Callon, 1986; Callon, Law, \& Rip, 1986; Latour \& Woolgar, 1986). Rather, these studies, alongside-related works, show how society and nature, and knowledge of reality, are effects of heterogeneous assemblages - that is they are co-constituted in entangled sociomaterial practices (Barad, 2003, 2007; Latour, 2005; Law, 2004; Law \& Mol, 2002; Mol, 2002).

Therefore, the broad aim of this chapter is to explore the co-constitutive nature of sociomaterial practices that produce the researcher, the researched, and the research methods. We bring a performative sensibility to data practices, co-opting nonrepresentational approaches developed by new materialist (Coole \& Frost, 2010; Fox \& Alldred, 2017) and post-qualitative research (Lather \& St. Pierre, 2013). A performative approach emphasises how things, spaces, bodies, and knowledges, '... come to matter through the world's iterative intra-activity, its performativity' (Interview with Karen Barad, in Dolphijn \& van der Tuin, 2012, p. 69).

\section{Methodological Backstory}

What follows begins with a brief methodological backstory to the gadfly-performance and an introduction to the analytic concepts of assemblage, 'sticky data', and affect. We then present our data work via a performative script, before finishing with a discussion of the possibilities emerging from doing data differently.

Drawing on Honan's (2014) paper, entitled Disrupting the habit of interviewing, as a model for how we might work empirical material differently, we engaged in a data-performance entailing a method of 'data talking, us talking data, and data 
talking back'. The concept of intra-action ${ }^{1}$ (Barad, 2007) became central to our approach. Not only does it convey the co-constitutive nature of data, researcher, and researched, it is enacted in practices. Hence, this chapter maps our collaborative data intra-actions with three mini data-vignettes (Masny, 2014) configured from a Taekwondo training session involving a group of high-performance athletes and their coach in the lead-up to a high-stakes competition. The data-vignettes enfold material from various sources (field notes, sound bites, interviews, and photographs) including our researcher conversations. Our collaborative approach of doing data differently resists temptations to close data in on themselves, thereby disrupting what Honan (2014) identifies as habitual approaches to working with data. In the process, data actively join the collaboration, bringing into play new concepts, affects, encounters, and relations inside-and-outside of the research sites.

\section{Thinking with Deleuze: Assemblage, Affect, and Stickiness}

Our data workings also draw on Deleuze and Guattari's (2013) closely linked concepts of assemblage and affect. An assemblage consists 'of multiple, heterogeneous parts linked together to form a whole' (Müller, 2015, p. 28). The research assemblage enfolds researcher, research tools, research site, participants, and the Transitions Research Symposium audience. Rather than existing as individual human subjects, research 'subjects' (such as coach and researcher) assemble 'in' the data performance, existing in relation with the broader research assemblage. For example, during the performance, the researcher body merges with living and inert others as researcher-pencil-notebook-laptop-chair-desk-assemblage, before deassembling and re-assembling in a different configuration of researcher-notebookpencil-audiorecorder-sweat-smell-assemblage, only to de-assemble and re-assemble again, and again ... (Somerville, 2016). Agencies are therefore distributed across the assemblage and are not defined by human action. In the research assemblage thus conceived, data are lively, consisting of living and non-living agentic elements, all exerting force (Bennett, 2010).

\section{Collaborative process}

We met in the staff dining area of the faculty a few times to work up some empirical data from Sarah's Ph.D. research for our eight-minute presentation at the Transitions Research Symposium conference. From the start of our collaborative work, we wanted to do more than 'just give a talk to some slides'-we wanted to perform so that data might remain vital (Bennett, 2010). Before our first meeting, we had each engaged with a selection of the empirical material on our own, taking up Honan's (2014) challenge to work data differently. We asked

\footnotetext{
${ }^{1}$ We work with Barad's $(2003,2007)$ concept of intra-action to convey the co-constitutive nature of data, researcher, and researched rather than interaction, which assumes that there are separate entities that interact.
} 
questions of data, and of each other, and allowed data's continual challenge back to us to find what else was at work in assembling the learning environment of the Taekwondo training session. When we met, we talked, laughed, challenged, questioned, wrote notes, explained our thinking to each other and allowed some questions to stay, not answered, not 'explained'. Through this process the script that follows materialised.

Affect, as a transmission of intensity (Deleuze \& Guattari, 2013), is one such force that we consciously attune to in this collaboration. Affect is integral to the assemblage because it acts as a pulse, becoming the source of its power, "making the socio-material hold together or fall apart' (Müller, 2015, p. 36). Foregrounding the affective workings of the research assemblage moves us to seek out those moments of disconcertion in the data (MacLure, 2013) prompting our responsiveness to data that get 'under the skin' (MacLure, 2011, p. 999) and 'stick' to us. The 'stickiness' of data is an affective relation that functions variously to hold-together, block, or bind entities by accumulating affective value (Ahmed, 2014). The notion of 'sticky learning' has recently been deployed in educational research for its capacity to generate 'a different way of attending to the production and transfer of learning' (Mulcahy, 2016, p. 208). In our case, the notion of 'sticky data' becomes salient because it takes us deeply into the complex and 'dynamic process of discursive practices and the materiality of the body' (Zembylas, 2007, p. 29, emphasis in the original) that unfold in the Taekwondo training session.

\section{Data Performances}

This section of the chapter re-presents the script that we, author-researchers, performed at the Transitions Research Symposium in June 2017. It is comprised of three intra-active data vignettes. Centreing our collaborative process on intra-action, we enact an ethics that is response-able for and accountable to '... the lively relationalities of becoming, of which we are a part' (Dolphijn \& van der Tuin, 2012, p. 70). We are interested in how enacting a very different methodology might become a point of entry for thinking-doing-caring learning environments research. So, throughout the data workings (the collaborative process) we instantiated the notion that 'Matters of fact, matters of concern, and matters of care are shot through with one another' (ibid., p. 69).

\section{Data Intra-action 1: What Is It About the Smell?}

[Sarah sits on stool holding journal-becoming researcher at Taekwondo. Carol moves to the researcher table and dons her researcher hat (literally a hat). A soundbite of athletes vocalising while they spar plays. Photo of training room on screen.] 
Sarah: Taekwondo training session

$-7.30 \mathrm{am}$

- 17 high-performance athletes, 12-28 years

- 1 coach

- 1 researcher

I sit in a rectangular shaped room with mirrors down each side. The floor has red and blue taekwondo mats. Training mitts, kicking bags, and protective gear hang in orderly rows. There are ceiling fans-not on. And air-conditioning units-also not on. There is a particular smell.

[Sarah joins Carol sitting at the researcher table-hat on, notebook and pen in hand.]

Carol: Air con and fans not on? What is it about the smell? Assaulting the senses?

How does the smell affect researcher, athletes, and coach? The air-conditioning and fans are not on - the 'not on' fans attract-how? Smell and (not on) fans become part of this training assemblage along with trainees, coach, equipment and competition. How is our researcher attention called to what is (not) there?

Sarah: We can understand data that attract attention and stay with the researcher as 'sticky data'. The data vignettes are composed of data that stick (and stink). Data stick to the researcher and the researcher sticks to data. Not only do data have the capacity to stick but they can also have sticking points. The smell, the air con not on, fans-not on, unwashed training gear releasing microscopic particles into the atmosphere can clot.

Carol: Our researcher expectations enter the assemblage. Something expected to be there that is not there, to be 'on' or working but not working, reveals a contingent reality - an expectation of the future but one that will vacillate-a future that is both fans on and fans off. This working of data that become part of assemblages brings to attention the constant contingency at work between human and nonhuman agencies which, according to Spinoza, involves the passions and patterning of fear and hope.

\section{Data Intra-action 2: Coach, Stopwatch, Whistle, and Stick}

[Sarah changes: puts on tracksuit top, becoming coach. Carol becomes researcher sitting on the stool taking notes. A soundbite of coach-voice plays. Photo shows athletes entangled in a sparring exchange.]

Carol: The coach walks into the training room and the chatter that is athletes' chatter that accompanies the warm-up stops dead. Today the athletes are instructed to listen, NOT question. The first drill is explained; they break off into sparring pairs and begin. The coach has a stopwatch, whistle and stick. Every minute she shouts "CHANGE!" and the sparring pairs swap roles. The intensity in the four walls of the training room is palpable. 
Sarah-Coach: (instructing in a loud voice)

- As I call out your name, you'll be on the defensive

- Keep going. No stopping. No talking!

- Frustrate your partner. Close your gaps. Frustrate, frustrate, frustrate!

- Change! The other line is frustrating now.

- Work the other person's patience. Look for the gaps in the attack.

- Change!

Carol: One sparring pair at the end of the room stop what they are doing. They've lost focus.

[Sarah changes: removes tracksuit top. Carol and Sarah move to research table and chairs-hats, notebooks, pens.]

Sarah: The clotting of coach-stopwatch-stick-whistle-shouting-pacing in a traditional martial arts training space 'appears' coach-centred. However, this rendering of the coach as coach-centred is incomplete; it reflects the notion of coach (teacher) as individual, intentional human subject. It misses the highly responsive bodywork that the coach is doing.

Carol: It brings to mind the work that teachers do in classrooms. What we as researchers see and hear is not all that is happening. We can also turn our attention to athlete (or student) bodies and their material-discursive practices. Moving with coach/resisting coach—becoming Taekwondo athletes differently? Identities are enacted through multiple connections with other bodies, other assemblages.

\section{Data Intra-action 3: And so Often They're Buggering it Up}

[Sarah becomes coach in tracksuit top—standing, leaning against researcher chair, she speaks about her practice. No soundbite. Photo of sweaty athlete bodies engaged in a group hug.]

Sarah-coach: "You can't overthink it because it becomes a little forced...

Sometimes I'll tap into the kids and I'll see that once they start fraying, that means they've lost control. So, I pull back a little. I stop counting the activities, I stop whistle blowing, I just keep it free. I'm conscious of not just yelling at them because then they'll become incredibly dependant on that. We don't want that. A class is designed around giving them a sense of empowerment over decision making. The decision is ultimately theirs, I just give them lots of options. Then we practice, then I put them under pressure. Then I'll pull back and see how they're going making that decision. And so often they're buggering it up. And then there's "BaaaH!" And that's fine. I'll come back in and reassert, reposition everybody. Changing partners is a big one because if they stay with the same partner they don't reboot." 


\section{[Sarah and Carol move to chairs. Hats, notebooks and pens.]}

Carol: Fear and hope are intense in this vignette.

Does the coach work to allay fear and build hope through her body? Giving a sense of empowerment-is that hope that athletes can make the right decisions on their own? She builds muscle memory_body workings, working bodies helping them to not overthink? She pulls back to give them a go but they keep 'buggering it up'. Is that her fear?

Sarah: She puts the pressure back on, practicing again.

She is 'tapping' into the athletes, palpating their body-talk, responding in kind by modifying her own practice, modifying the intensity of the affective flows within the training assemblage, sometimes modifying the assemblage altogether.

Sarah: And then there is the assembling of sweat-bodies.

Athlete-partner-frustrating-sweating-in control/buggering it up! Athlete and coach bodies produce sweat, smell, and feelings that fold into other assemblages. It is not clear where bodies begin and end. The smell of Taekwondo hugs you. It is a seeping of sweat between athlete bodies into protective gear, permeating the atmosphere and thickening the air. It inhabits the data but you can't see or smell it in this data performance.

Carol: Thank god!

Sarah: It is both flashback and premonition that palpates stink-bodies in ever shifting patterns of fear and hope.

[Sarah and Carol move to lectern and conclude the performance. No hats.]

\section{Discussion}

Our discussion focuses on the bodily practices of the coach. The coach in the vignettes above is not assumed to be pre-existing human subject. Rather coach emerges through processual gatherings of sweat, movements, and practices of coaching. Coach is a code word with a history. All that can be known of 'coach' prior to the research are generalities, the way things are expected to be, the standards and histories of what has gone before. Codes take the place of action and work to silence affects and delete practices - codes have a politics. As Law and Mol (1998) propose, codes involve betrayal because they tell only of limited aspects and leave out so much. What codes cannot write easily are smells, sweat, oscillations of fear-and-hope, and the highly attuned bodywork that co-constitute coach (or 'teacher' if this argument is extended to teaching practices in school learning environments). In our research approach, coaching is performed in processes of continually becoming-in-practices involving 
a myriad of intra-connected heterogeneous elements. Coach, and/or teacher, emerges as an intra-connected relational assemblage performed in multiple practices.

As we have described throughout this chapter, our methodology differs from conventional research which tends to position the researcher outside of the data (Cohen, Manion, \& Morrison, 2007). This positioning of the researcher deploys pre-established frameworks with the purpose of distilling complex data into generalised 'facts'. Our issue with conventional learning environments research is that the focus is placed on human (mis)use of spatial affordances as though humans, spaces, and materials pre-exist learning and teaching practices. In this way the research quickly stabilises objects and subjects (in codewords) that are contestable and unstable, never quite fixed and certain. Yet, while seeking to reveal best-practice of how coach-teacher and athlete-learner inhabits and uses spaces is a worthy aim for creating greater certainty for educators and policy-makers to make decisions (Ellis \& Goodyear, 2018), the danger is that materials and texts will continue to be characterised as separate from, rather than co-constitutive of, teaching and learning (Mahat, Grocott, \& Imms, 2017). Research needs to find ways to story the intensity of relationships between learning spaces, teaching-learning activities, and heterogeneous bodies that do not fit pre-existing frameworks; find ways to allow data to speak rather than leaving it on the cutting room floor.

Research that reduces teaching and learning to simplified meanings is particularly troubling to us, especially given our thinking-doing-caring sense of the coconstitutive entanglement of matter. Where research methods reduce teachers' work to what can be made visible to the eye and measurable, some aspects of the coach's or the teacher's pedagogic practices ${ }^{2}$ become threatened. The visible and measurable become new norms established within lists of standards which simultaneously work to reduce the complexity of teaching and learning practices. A possible outcome is the decrease of teacher's capacity to respond to the affective demands of the moment, such as coach describes her practices of: '... tap [ing] into the kids ... once they start fraying, that means they've lost control. So, I pull back a little. I stop counting the activities, I stop whistle blowing, I just keep it free'.

Coach works the athletes who move in response to her voice-coach-voiceathlete-body-moves, co-constituting the Taekwondo training space. The directions she gives have a spatio-temporal history, folding space-time connecting Korean culture and (post) colonial history with a club in Melbourne, Australia, looking towards a future at the international competitions - a future tinged with hope and fear-folding athletes' well-rehearsed bodies, knowledge of the moves, of how to attack and defend, with coach body keeping them moving, pressuring, until she senses their loss of focus, 'once they start fraying'. Her work is intense, from moment to moment, sensing the affective moves of athlete bodies, responding to changes, noticing their reduced concentration, 'so I pull back a little'.

\footnotetext{
${ }^{2}$ Our understanding of pedagogy is of pedagogy as a relational process that is inseparable from learning. In our understanding, drawing on assemblage, pedagogy is enacted in relation to the world (Pickering \& Guzik, 2008). As such, becoming a trained body, as in the Taekwondo training session, or becoming a competent reader in a focused reading lesson, is performed in affective relations with intra-active multiple material-discursive entities.
} 
Compare the affective-intensities of the coach-athletes to the ways in which the classroom teacher is inscribed by contemporary learner-centred, twenty-first-century skills-based discourses. These contemporary discourses focus on what is visible, inscribing the teacher's mind (leaving out the body) as a facilitator who seeks and measures the learning of the learner, and uses that data to reflect on her own teaching. Teacher, in this scenario where only the learning that can be made visible and measurable is valued, is in danger of being reduced to the teacher reflected in the eyes of the responsibilised learner. In this view, teacher becomes non-teacher (Rømer, 2018, p. 7).

Nevertheless, we are not saying that contemporary teachers are victims of some malevolent re-assemblage of educational ideas forcing them to change, to be passive facilitators focused on learners in innovative learning environments, for there is no guarantee that 'innovative learning environments assemblages' exist in practices, or, if they will endure (Callon, 1986; Latour, 2005; Law, 1994). For, as we have shown in the body of the coach, and encountered in our own teaching, pedagogy is affective and lively, intra-connected across space-times with a multitude of other, different, assemblages which at the very least leave open an array of possibilities for teaching and learning. What we have tried to evoke in our performance is what some researchers of everyday assemblages in the life of schools (see for example: Mulcahy, 2012; Mulcahy \& Morrison, 2017; Watkins, 2011, 2017) have illuminated well; that the affective capacities of bodies are indeterminate and ceaselessly inventive (Zembylas, 2017).

\section{Conclusion}

Our methodological data-working has helped us to attune our thinking-doing-caring to the minutiae of everyday practices, their affects and their material effects. Practices are 'Janus-faced' (Latour, 1987), facing in two directions at once with many consequences that cannot be known beforehand. For us as teachers, this is the joy and threat of the lively, embodied world-making what is always possibly otherwise. We want to argue that the teacher or coach or researcher self as a subject remains a 'site of possibilities' (Watkins, 2010), engaged in a process of mutual 'becoming with' the lived world.

Gadfly, as worked through this performance, provoked different ways of thinkingdoing-caring data, by attuning us to bodily affects (including our own). We share the belief that an uncritical use of analytic strategies like coding and classifying data do not represent a reality out there, rather all research helps create the phenomena under investigation. As Law proposes, conventional thematic or statistical analytical methods are not wrong, 'rather, they and the relations in which they are located ... both enable and constrain' (Law, 2004, p. 39) the conditions of possibility. That being so, a responsive and relational collaborative methodology that seeks to stay with the messiness and uncertainty of affects, of smells and sounds and pressuring and losing focus, can bring into view the everyday practices making, unmaking, and remaking learning environments. The point we make is that we researchers need to become 
aware of the realities we enact in our research practices, and the political work that these enactments of reality do. Methods that reduce complexity are political, 'since any attempt to reduce the number of available options for action for the 'elements' within a system is about the exertion of power' (Biesta, 2010, p. 498). Therefore, it is imperative that we attend to the politics of our research practices and their ontological as well as their epistemological implications.

Diverse research practices help us to think differently, and become researchers differently, by interrogating and disrupting what is emerging, assembling, and clotting. An integral part of this is our process of collaborating, an iterative process that involved data taking on the figuration of the gadfly too-showing that we as researchers also do not know what we think we know. This process became a powerful research tool that enabled us to enact an intra-active researcher subjectivity; of collaborations as sites of emergence that continually '... creates and recreates itself and its co-labourers as part of the currents and waves of the seas' (Neimanis, 2012, p. 217).

A further implication of this chapter's experimental practice is its potential to open a space for critical dialogue among the learning environments research community. Critical dialogue is needed to question commonly held assumptions that there are naturally occurring divisions between the researcher and researched, what our participants tell us and what we ask them, what and how we think and write in research texts, and participants' and researcher bodies (and minds). The performance-chapter is provocative in its attempt to unsettle pre-existing assumptions that reality can simply be represented in our research reports, distilled into fact sheets, or pinned down as a set of best practices. Moreover, it demonstrates how we may research educational settings, materials, texts, and body-minds as entangled assemblagescontinually co-constituting each other in messy and often uncertain sociomaterial practices.

Acknowledgements Data involved in this research was obtained adhering to the required ethical protocol of the authors' host institution.

\section{References}

Ahmed, S. (2014). The cultural politics of emotion. Edinburgh: Edinburgh University Press.

Barad, K. (2003). Posthumanist performativity: Toward an understanding of how matter comes to matter. Signs, 28(3), 801-831.

Barad, K. (2007). Meeting the universe halfway: Quantum physics and the entanglement of matter and mearning. Durham: Duke University Press.

Bennett, J. (2010). Vibrant matter: A political ecology of things. Durham and London: Duke University Press.

Biesta, G. J. J. (2010). Why 'what works' still won't work: From evidence-based education to valuebased education. Studies in Philosophy and Education 29, 491-503. https://doi.org/10.1007/s11 217-010-9191-x.

Callon, M. (1986). Some elements of a sociology of translation: Domestication of the scallops and the fishermen of St Brieuc bay. Sociological Review Monograph, 32(2), 196-233.

Callon, M., Law, J., \& Rip, A. (Eds.). (1986). Mapping the dynamics of science and technology: Sociology of science in the real world. Basingstoke: Macmillan Press Ltd. 
Cohen, L., Manion, L., \& Morrison, K. (2007). Research Methods in Education (6th ed.). Abingdon, Oxon: Routledge.

Coole, D., \& Frost, S. (Eds.). (2010). New materialisms: Ontology, agency, and politics. Durham: Duke University Press.

Deleuze, G. (1988). Spinoza: Practical philosophy (R. Hurley, Trans.). San Francisco: City Lights Books.

Deleuze, G., \& Guattari, F. (2013). A thousand plateaus: Capitalism and schizophrenia (B. Massumi, Trans.). London, New Delhi, New York and Sydney: Bloomsbury.

Dolphijn, R., \& van der Tuin, I. (2012). New materialism: Interviews \& cartographies. Ann Arbour, MI: Open Humanities Press.

Ellis, R. A., \& Goodyear, P. (Eds.). (2018). Spaces ofteaching and learning: Integrating perspectives on research and practice. Singapore: Springer.

Elmore, R. F. (2018). Design as learning: Learning as design. In R. A. Ellis \& P. Goodyear (Eds.), Spaces of teaching and learning: Integrating perspectives on research and practice. Singapore: Springer.

Fox, N. J., \& Alldred, P. (2017). Sociology and the new materialism: Theory, research, action. London and Thousand Oaks, CA: Sage.

Honan, E. (2014). Disrupting the habit of interviewing. Reconceptualizing Educational Research Methodology, 5(1). Retrieved from http://journals.hioa.no/index.php/rerm.

Lather, P., \& St. Pierre, E. A. (2013). Post-qualitative research. International Journal of Qualitative Studies in Education, 26(6), 629-633. https://doi.org/10.1080/09518398.2013.788752.

Latour, B. (1987). Science in action: How to follow scientists and engineers through society. Cambridge, MA: Harvard University Press.

Latour, B. (2005). Reassembling the social: An introduction to actor-network-theory. Oxford: Oxford University Press.

Latour, B., \& Woolgar, S. (1986). Laboratory life: The construction of scientific facts. Princeton, NJ: Princeton University Press.

Law, J. (1994). Organizing Modernity. Oxford and Cambridge: Blackwell.

Law, J. (2004). After method: Mess in social science research. Abingdon, OX: Routledge.

Law, J., \& Mol, A. (1998). On metrics and fluids: Notes on otherness. In R. Chia (Ed.), Organized world. London: Routledge.

Law, J., \& Mol, A. (2002). Complexities: Social studies of knowledge practices. Durham: Duke University Press.

MacLure, M. (2011). Qualitative inquiry: Where are the ruins? Qualitative Inquiry, 17(10), 9971005. https://doi.org/10.1177/1077800411423198.

MacLure, M. (2013). The wonder of data. Cultural Studies $\leftrightarrow$ Critical Methodologies, 13(4), 228-232. https://doi.org/10.1177/1532708613487863.

Mahat, M., Grocott, L., \& Imms, W. (2017). "In the real world...": Teachers' perceptions of ILEs. ILETC Phase 1 teacher workshops. Retrieved from http://www.iletc.com.au/publications/ reports/.

Masny, D. (2014). Disrupting ethnography through rhizoanalysis. Qualitative Research in Education, 3(3), 345-363. https://doi.org/10.4471/qre.2014.51.

Mol, A. (2002). The body multiple: Ontology in medical practice. Durham and London: Duke University Press.

Mulcahy, D. (2012). Affective assemblages: body matters in the pedagogic practices of contemporary school classrooms. Pedagogy, Culture \& Society, 20(1), 9-27.

Mulcahy, D. (2016). 'Sticky' learning: Assembling bodies, objects and affects at the museum and beyond. In J. Coffey, S. Budgeon, \& H. Cahill (Eds.), Learning bodies: The body in childhood and youth studies. Singapore: Springer.

Mulcahy, D. (2018). Assembling spaces of learning 'in' museums and schools: A practice-based sociomaterial perspective. In R. A. Ellis \& P. Goodyear (Eds.), Spaces of teaching and learning: Integrating perspectives on research and practice. Singapore: Springer.

Mulcahy, D., \& Morrison, C. (2017). Re/assembling 'innovative' learning environments: Affective practice and its politics. Educational Philosophy and Theory, 49(8), 749-758. https://doi.org/10. 1080/00131857.2016.1278354. 
Müller, M. (2015). Assemblages and actor-networks: Rethinking socio-material power, politics and space. Geography Compass, 9(1), 27-41. https://doi.org/10.1111/gec3.12192.

Neimanis, A. (2012). On collaboration (for Barbara Godard). NORA-Nordic Journal of Feminist and Gender Research, 20(3), 215-221. https://doi.org/10.1080/08038740.2012.703689.

Pickering, A., \& Guzik, K. (2008). The mangle in practice: Science, society, and becoming. Durham: Duke University Press.

Plato. (1984). The dialogues of Plato (R. E. Allen, Trans.). New Haven: Harvard University Press.

Rømer, T. A. (2018). A critique of John Hattie's theory of visible learning. Educational Philosophy and Theory, 1-12. http://doi.org/10.1080/00131857.2018.1488216.

Somerville, M. (2016). The post-human I: Encountering 'data' in new materialism. International Journal of Qualitative Studies in Education, 29(9), 1161-1172. https://doi.org/10.1080/095 18398.2016.1201611.

Watkins, M. (2010). Desiring recognition: Accumulating affect. In M. Gregg \& G. J. Seigworth (Eds.), The affect theory reader. Durham and London: Duke University Press.

Watkins, M. (2011). Teachers' tears and the affective spatiality of the classroom. Emotion, Space and Society, 4(3), 137-143.

Watkins, M. (2017). Can space teach? Theorising pedagogies of social order. Geographical Research, 55(1), 80-88. https://doi.org/10.1111/1745-5871.12197.

Zembylas, M. (2007). The specters of bodies and affects in the classroom: A rhizo-ethological approach. Pedagogy, Culture \& Society, 15(1), 19-35. https://doi.org/10.1080/146813606011 62030.

Zembylas, M. (2017). The contribution of non-representational theories in education: Some affective, ethical and political implications. Studies in Philosophy of Education, 36, 393-407. https:// doi.org/10.1007/s11217-016-9535-2.

Sarah Healy and Caroline Morrison (Australia) are both early career researchers who share an interest in theoretical concerns related to (new) materialities. Their respective research endeavours intersect on an onto-methodological level. In their contribution to this book, they put collaborative research into practice, exploring the in-between spaces of researchers, research contexts, and 'data' generated in a setting where teaching and learning occurs with palpable intensity-a taekwondo club. Prior to embarking on her $\mathrm{PhD}$ at The University of Melbourne, Carol was a primary teacher for 17 years and a primary school principal for 8 years. She is now researching policy practices of new generation learning environments in Melbourne Catholic schools. Sarah's background is in the creative industries and art education. Her $\mathrm{PhD}$ research, completed at The University of Melbourne in 2019, explored the ethics of pedagogic practices that occur 'in' intense learning environments. Sarah is currently a Research Fellow at The University of Melbourne's Graduate School of Education.

Open Access This chapter is licensed under the terms of the Creative Commons Attribution 4.0 International License (http://creativecommons.org/licenses/by/4.0/), which permits use, sharing, adaptation, distribution and reproduction in any medium or format, as long as you give appropriate credit to the original author(s) and the source, provide a link to the Creative Commons license and indicate if changes were made.

The images or other third party material in this chapter are included in the chapter's Creative Commons license, unless indicated otherwise in a credit line to the material. If material is not included in the chapter's Creative Commons license and your intended use is not permitted by statutory regulation or exceeds the permitted use, you will need to obtain permission directly from the copyright holder.

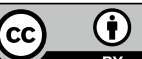

